\title{
Aliens in decline and socially-ascending humans. (Class, race, gender, the sociology of DS9.)
}

\author{
Camille Akmut
}

\begin{abstract}
A theory is put forward according to which Star Trek's DS9 is the meeting place of at least two major populations : socially-declining aliens who seek a reclassification through Federation institutions (Starfleet and adjacent agencies in particular), and humans on a late stage upward trajectory (culminating in e.g. dilettante / artist offspring).
\end{abstract}




\section{Introduction : a historical detour}

Star Trek's 24th century has more in common with 20th century sociology than might be obvious at first, with its representation of an ideal Earth society where poverty, inequality and resulting conflicts have "long" been eliminated, we are told $^{1}$.

Past faulty government forms and economies have either been replaced by benevolent scientific exploration (guaranteed, in theory, by both the laws of the Federation Charter and the principle of the Prime Directive) or luxury communist leisure (offered to tourists of Risa, where the old philosophical fantasy of "shared wives" has been realized, and two suns always shine); nonetheless these societies continue to answer to most of the rules and laws established by sociologists.

Here, the television series $D S 9$ is reinterpreted as meeting place of not humans and aliens - a naive albeit correct description of this work of science fiction - but as two demographics situated in different stages of their social trajectories.

In particular, we argue that the contrasting fates of the duo Jake and Nog offers a strong case for such an interpretation. The tragic fall of the House of Mogh is another. Dr. Bashir is a barely veiled second-generation immigrant success story.

${ }^{1} D S 9$ provides us with the information that a major event in this shift towards a peaceful and equal Earth occurred during the so-called Bell riots of their 21st century. [Note that not all planets have reached this stage of evolution, or all humans living in the Milky Way : the existence of a rebellion in the form of the Maquis is a constant reminder of this, in DS9 and beyond.] 


\section{"Hello Boyyyyyyys!" Rom and Quark, and Ishka}

The space station DS9, having been recently liberated from a previous occupation by the Cardassians, is in need of shopkeepers on the Promenade, to service the Federation staff : its captain, Benjamin Sisko, strikes a deal with one of the few remaining merchants, an alien called Quark, who is on the brink of leaving due to political unrest ( "they hang people like us first").

Quark is a Ferengi who on DS9 is elevated to "community leader", a largely symbolic (though an association is supposed to exist) and somewhat ridicule title (considering his dubious reputation), and given preferential treatment on the lease of a bar.

However, on his homeworld planet of Ferenginar, where capitalism reigns supreme, there are few families more hated than this one :

Rom, Quark's brother, obviously does not care much for Ferengi values (wherein greediness is a virtue, and every Earth moral is turned on its head), or business matters altogether : an undervalued, virtuoso engineer working as a bartender's aide.

Ishika, their mother, is a first-wave feminist who gradually rejects the strict underlying patriarchy of Ferengi government : females are forbidden to earn profit and cannot wear clothing among other things. The first rule makes employment impossible, the second renders travel de facto also impossible.

Their father, we learn later, was a failure (from the point of view of Ferengi society / values).

Brunt, a high bureaucrat, wishes to make them bankrupt (a procedure equivalent to loss of citizenship on Ferenginar).

Quark in the midst of all this adopts "more-Ferengi-than-though" attitudes as a reaction, though this progressively turns out to be unsustainable culminating in grotesque episodes such as e.g. a transformation into a crossdressed financial advisor...

Rom realizes the material contradictions pf Ferengi society much sooner (a society that prides itself in cold, reasonable profit-making while excluding an entire gender from business and devaluing science resulting in spaceship craft far behind that of other worlds) and decides to join the Station's maintenance crew instead where he quickly rises from nightshift (the least desirable position) to engineer proper.

Rom leaves Ferengi society and its classifications behind, as he starts to experiment with his diet adding human food to it (worms are replaced with bacon for breakfast, snail juice with OJ or root beer?) and ends up marrying outside of the Ferengi race with a Bajoran.

(He goes even as far as citing Marx in an episode where he unionizes the bar.)

Ishka meanwhile leads a successful revolution on Ferenginar for gender equality and a more socialist form of government including progressive taxation, a success 
all the more notable as taxes did not exist before (the unspeakable "t-word", as Q. puts it) ${ }^{2}$.

This transition was further facilitated by her inextricably romantic and political alliance with Ferenginar's leader, Grand Nagus Zek.

By the End of the series, Ishka and Zek have transformed their world in such a way that the previously outsider Rom now comes to be seen as the best representative of the New Ferenginar, "a more gentle" one, and is chosen as successor to Zek who now wishes to sunset and retire on a vacation planet (Risa, where an artificially controlled weather makes for a never-ending Summer among friendly, square-jawed or bikini-clad natives of all genders).

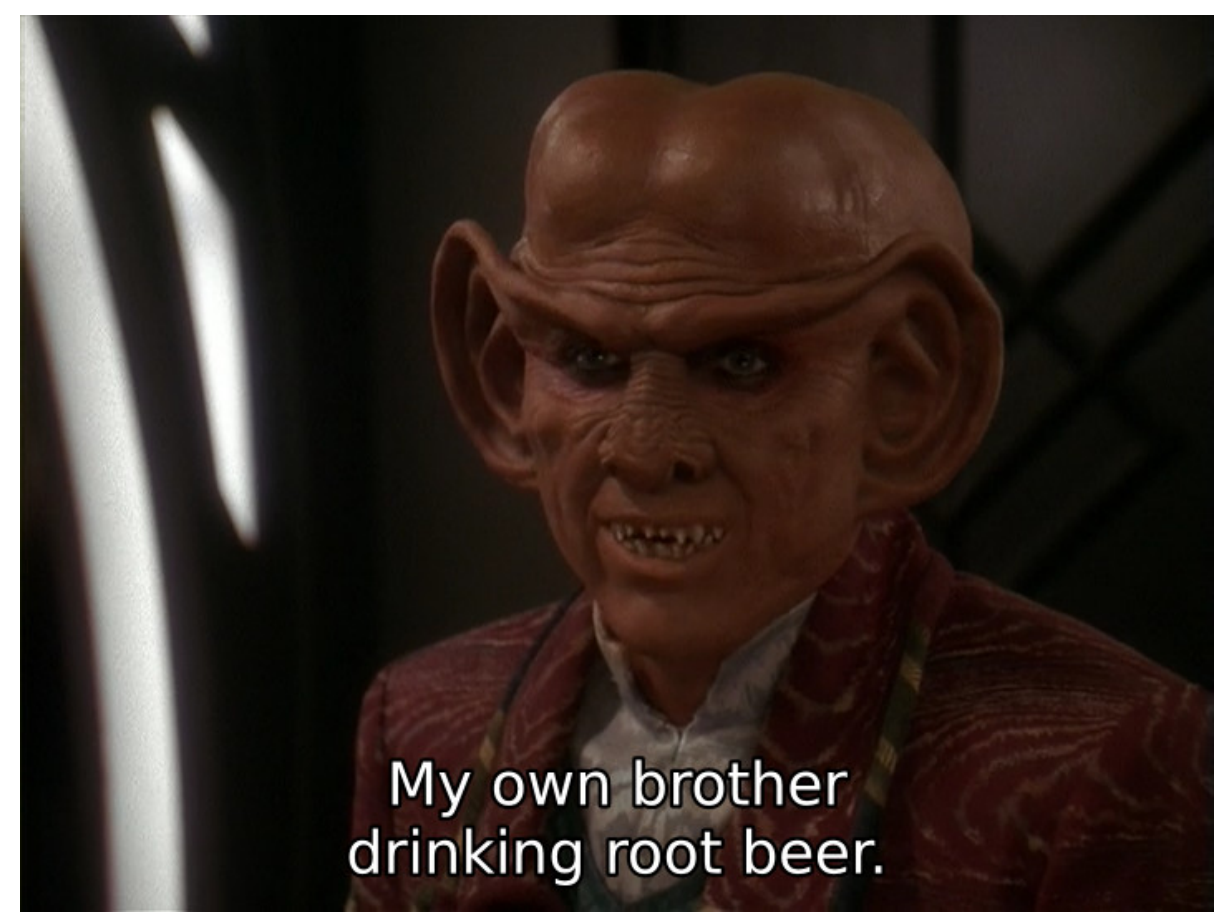

\footnotetext{
${ }^{2}$ we use "interracial" here to describe the union of members of two different races (Klingon and human), not humans...
} 


\section{Worf, an honorable outsider, and Dr. Julian Bashir's rise}

(Worf was a character present in Star Trek's The Next Generation, we focus here mainly on the happenings of DS9.)

The fall of the House of Mogh is well advanced by the time DS9 starts : Worf was raised by human parents, never fitting fully in either Earth or Klingon society, too human for the latter and not Klingon warrior enough for the other, resulting in a status of permanent outsider no matter where he goes.

He only finds the respect he craves - honor being a prime value of Klingon morality - by joining Starfleet, where he rises to Commander, and sometimes Captain, and finally Ambassador.

His son Alexander is the product of an interracial relationship ${ }^{3}$, creating further abstractions from traditional Klingon society. In fact, for most of DS9 the existence of Worf's son is not a topic, with the boy making a reappearance as a misfit Klingon soldier on a warship. (He cannot wield a batleth, the traditional Klingon weapon, and mistakes a simulation program for an actual attack.)

Worf is regularly involved in Klingon political and military affairs, where Klingons rarely fail to remind him of his uniform and new affiliation, and where he is mostly regarded as a traitor;

Only at the very end is be considered a hero (through fighting the corrupt Gowron who uses war as a tool for his own political advancement, the possibly worst crime for any leader), yet he turns down the position of Klingon emperor that is offered to him. This event is important in more than one way as Martok's reign heralds the beginning of a Klingon empire and society extracted from strict nobility-based hierarchies. (Just as Rom represents a new leadership, so does Martok with regard to the Klingon people, and elsewhere Damar for Cardassia.)

Back on the Klingon homeworld, the House of Mogh is in such decay that Worf's brother falls into a melancholia from which he cannot escape and makes multiple suicide attempts. To save him, his memories are wiped and he his given a new identity as the son of a different House.

Here reclassification happens very literally, at a biological level (the operation is said to be almost impossible to reverse.)

Finally, it could be argued that the figure of Worf in DS9 is an analogy for individuals who are the product of different cultures; Baldwin was never more American than when in Europe, and never less American than when in the United States... And, never more black amongst whites.

"When [my father] died I had been away from home for a little over a year. In that year I had had the time to become aware of the meaning of all my father's bitter warnings (...) I had discovered the weight of white people in the world." 4

\footnotetext{
${ }^{3}$ we use "interracial" here to describe the union of members of two different races (Klingon and human), not humans...

${ }^{4}$ Notes of a Native Son. (Baldwin's father was also, coincidentally, from New Orleans.)
} 
Ziyal, half-Cardassian and -Bajoran, two enemy races, plays a similarly conflicted, tragic figure... In our 21st c. literature, she would most likely be fictionalized as Jewish and Palestinian. She is killed by a radical, traditionalist Cardassian (Damar, who later reforms).

Dr. Bashir is a barely veiled second-generation immigrant success story, with a British sensibility :

This becomes clearest in the episode where, with his scientific career already far advanced (Bashir has made discoveries relating to extra-terrestial morphology, ills, viruses, ... that have come about as part of his service on a station, DS9, where many aliens live or pass through, as well as outside of it e.g. his cure for the engineered 'Quickening' affliction) and he is rewarded with a hologram of his own : to cope with lack of personnel or war-time conditions Starfleet has come up with a novel tool called "emergency medical adviser", this artificial intelligence is now to be modeled after none other than our Doctor.

This event however has unintended consequences, as his parents are asked for a testimony, to great dismay and embarrassment.

Julian's father has had a spotty career whose small achievements he constantly exaggerates : a temp. job on a freighter becomes a captainship, a gardener an architect etc..

Less is known about his mother, a demure middle-aged woman who tries to temper the passions of both husband and son.

But the expected stories of hard work and dedication that might accompany such tales on our planet, and our century, are replaced with a family drama centered around the taboo subject of genetic engineering, called "genetic enhancement" - a procedure rendered illegal in a previous century after an event referred to only as the "genetic wars"(?).

Finally, he finds solace inside a group of merry savants, similarly genetically enhanced individuals, whose modifications however have left them with debilitating features : one male is a sociopath, the other stuck in what appears to be an infantile stage, a young woman (Sarina) is catatonic while the other female of the group is somewhere on a spectrum of being addicted to sex or constant validation-seeking from the opposite gender (the producers of the show did not go as far as to specify, even though $D S 9$ is often called "darker"). 


\section{Jake and Nog : dilettante artist vs. ascetic officer}

DS9 is the meeting place of at least two major populations : socially-declining aliens who seek a reclassification through Federation institutions (Rom, Word and now Nog), and humans on a late stage upward trajectory...

At its most visible in the duo of Jake - the captain's son - and Nog - Rom's son, whose friendships and differentiated fates followed from childhood o adulthood may well be the only thread that runs through the entirety of DS9's story.

Nog starts as a petty thief in the midst of the chaos that ensues on the space station following the departing acts of sabotage by the Cardassians. As previously hinted, Quark only agrees to stay to save his nephew from a prison sentence.

When Jakes and Nog become friends, the former is presented as a good-natured, reticent co-conspirator of Nog's various schemes; Nog a delinquent who no one expects anything from, except becoming a mirror image of his uncle.

Both undergo tremendous transformations :

Jake's trajectory is the culmination of a father who is a Starfleet captain (a position more envied than Admiral, as one gets to pilot a ship rather than sitting behind a desk) and a grandfather cook ('Creole Kitchen' in New Orleans) :

Located at the end of this ascension Jake finds himself torn between being an artist, a writer, who sometimes comes dangerously close to being a dilettante, and more practical or political activities such as war-time reporting.

Nog, on the other hand, goes on to become the first Ferengi Starfleet officer (a fate similar to that of Worf as a Klingon within that same institution). Compared to his father, Nog went through Academy tests and training, which opens up a wide world of opportunities for him (similar in some way to the schools where future military and political elite can be found, on our world).

He is driven by a wish to serve, learn and improve and bears little in common with his former self. This affects his relationship with Jake, unveiled as he returns and they become roommates..

Frictions steadily grow between adult Jake and Nog who find it hard to live together : J. untidy and chaotic, N. disciplined and demanding. 


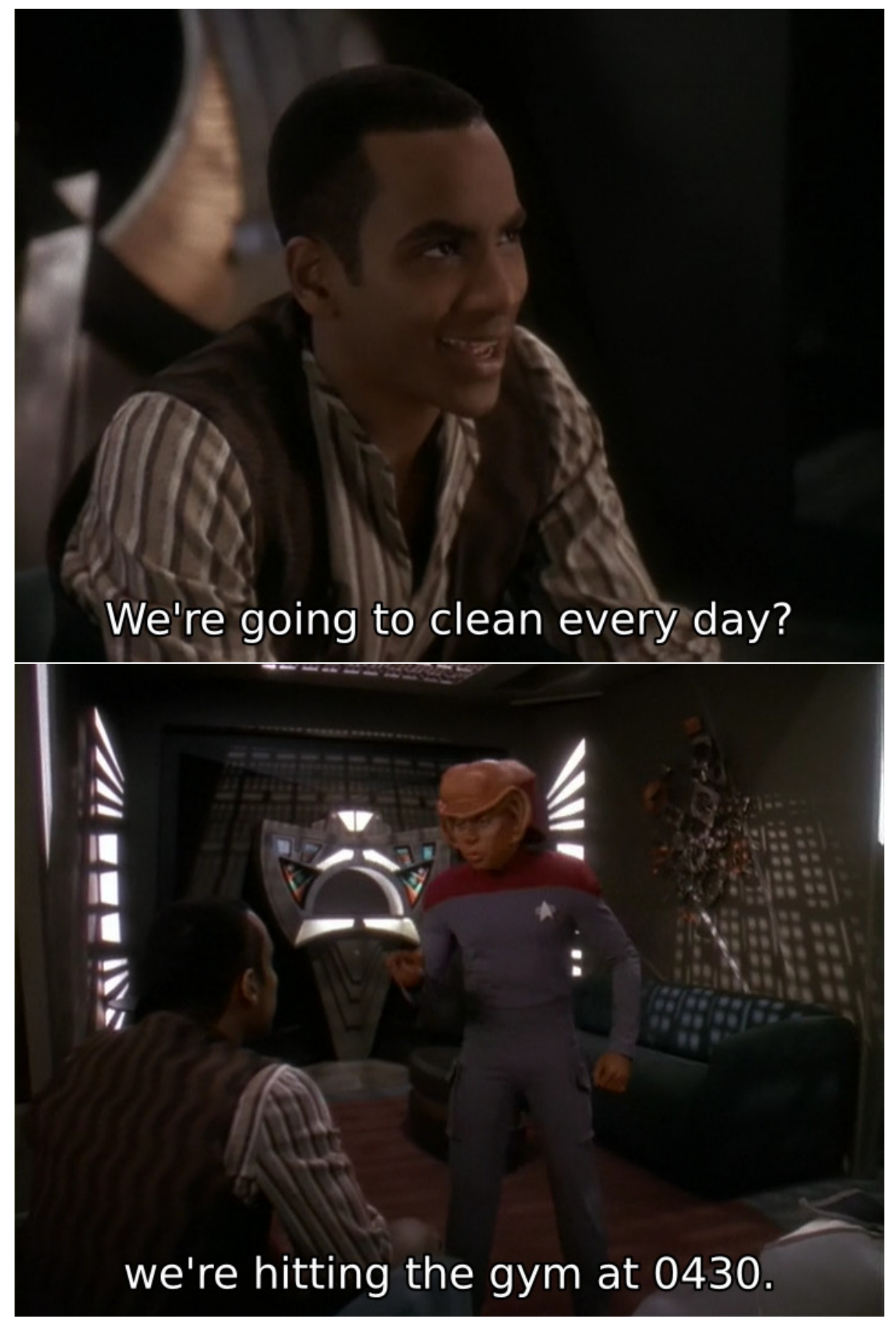

Other cases that may have been presented include, as for aliens, in particular Garak, an exilee from Cardassia, recently re-evaluated as a homosexual or bi.. 


\section{Conclusion}

The term elite means small number, thus periodic crises happen whenever new entrants integrate their circle : their assimilation is often necessary (e.g. rendered necessary by a penniless old aristocracy, or a liberal call for "diversity"), but their presence devalues the entire group by increasing numbers.

In Early Modern Europe, the emergence of a "robe nobility" (as opposed to the old "sword nobility" of Feudalism), requiring by a growing State apparatus in need of a skilled and learned elite principally recruited from Law backgrounds, could be named.

In our 21st century, where powerful aristocracies are of yesterday, in the West, the creation of a female elite and a "black bourgeoisie* (C. West) have been effective crowd controls.

The economist Milton Friedman thought he had found paradise in Hong Kong (regularly ranked as Earth's "freest" region, scoring high on property rights and police, but that any sane observer would regard as an extreme experiment in capitalism).

On Ferenginar capitalism has finally last reached its purest form, unencumbered by discontent, having penetrated all spheres of society, religion (their God, a "Blessed Exchecker", their paradise, the "Divine Treasury"), love (a contract or acquisition), family (where "selfish" is a compliment).

One of the defining characteristics of capitalism is no doubt its great ability to adapt as necessary, sometimes harsh, sometimes gentle, though always exploitative in one manner or another : sometimes rubber bullets, and sometimes tanks; knee-on-the-neck here, pink pat-on-the-back "we love you" there.

A beloved science-fiction series was interpreted anew from the traditions of Marxist sociology and history :

So long as communism does not exist, we can continue watching it on TV while asking ourselves if our "actions will follow our words"... 


\section{Ref.}

Deep Space Nine.

Season 3, Episode 11 and 12. "Past Tense".

S4 E24. "The Quickening".

S5 E16. "Doctor Bashir, I Presume?".

S5 E19. "The Ascent".

S6 E3. "Sons and Daughters".

S6 E6. "Sacrifice of Angels".

S6 E7. "You Are Cordially Invited".

S6 E9 and S7E5. "Statistical Probabilities" / "Chrysalis".

Engels, F.. Draft of a Communist Confession of Faith. (Q. : Is violence necessary?)

Baldwin, J.. Notes of a Native Son

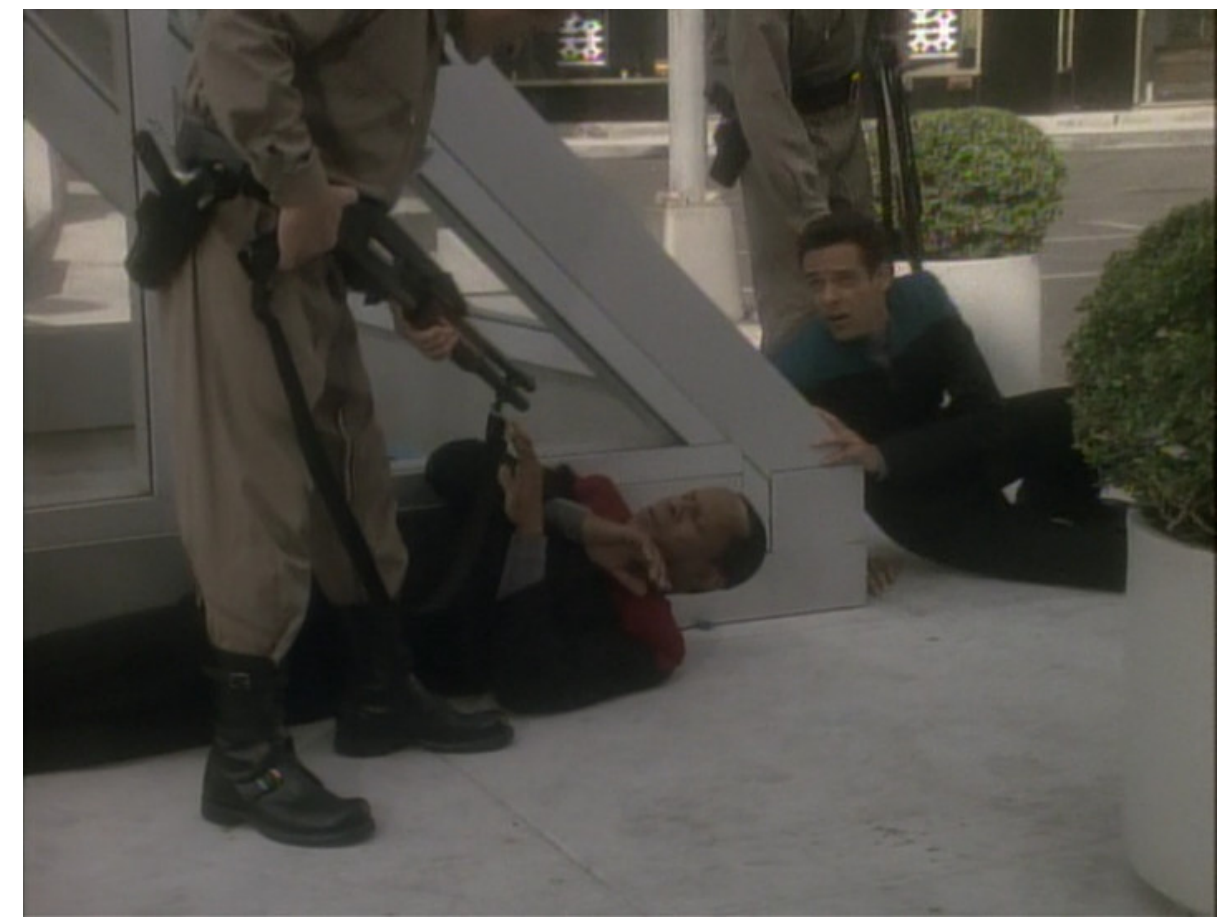

02/09/2021 